Initial management, however, should vary with local experience and changing patterns. For example, New Zealanders of Caucasian and Maori origins have comparably high rates of testicular tumours, ${ }^{5}$ and for them orchidectomy should be used. But in the USA, where different races have differing rates of testicular cancer, ${ }^{1}$ management varies.

${ }^{1}$ Mostofi, F K, and Price, E B, Tumors of the Male Genital System. Washington, DC, Armed Forces Institute of Pathology, 1973.

2 Jalota, R, Middleton, R G, and McDivitt, R W, Cancer (Philadelphia), $1974,34,464$

${ }^{3}$ Doll, R, Proceedings of the Royal Society of Medicine, 1972, 65, 49

${ }^{4}$ Burkitt, D P, Proceedings of the Royal Society of Medicine, 1973, 66, 312.

${ }^{5}$ Petersen, G R, and Lee, J A H, New Zealand Medical Fournal, 1973, 78, 401.
Ministry of Health, General Hospital, Enugu, Nigeria

WILSON I B ONUIGBO, FRCPATH, chief pathologist pregnancy. Case 2 was probably a case of reinfection. ${ }^{45} \mathrm{~A}$ maternal viraemia must have occurred, because there were antibodies in the IgM fraction of the cord blood. Or a primary infection might have occurred in the eighth week of pregnancy. The absence of congenital disorders, the absence of exanthema in pregnancy, and the fact that antibodies were found only in the IgG fraction are arguments against this.

Three conclusions can be drawn from these two cases. Firstly, determining the IgM level in the cord blood can be useful in the case of suspected congenital rubella infections. Secondly, if the IgM level is increased in the child's serum rubella antibodies should be looked for in the IgM fraction. Thirdly, it is doubtful whether a titre of haemagglutinating antibodies of $1 / 16$ offers sufficient protection against reinfection with viraemia.

${ }^{1}$ Gupta, J D, et al, Fournal of Clinical Pathology, 1971, 24, 547.

2 Snijder, J A M, Nederlandsch Tijdschrift voor Geneeskunde, 1974, 26, 995.

${ }^{3}$ Peetermans, J, and Huygelen, C, Presse Médicale, 1967, 75, 2177.

${ }^{4}$ Haukenes, G, and Haram, K O, New England fournal of Medicine, 1972, 287, 1204

${ }^{5}$ Pead, P J, Lancet, 1973, 2, 149.

(Accepted 31 August 1976)

Regional Laboratory of Public Health, V Ketwich, Verschuurlaan 92-Groningen, Netherlands

J A M SNIJDER, MD, head of department of immunology

F P SCHRÖDER, MSC, head of department of virology

Paediatric Hospital, W A Scholten, Rijksstraatweg 63, Haren, Netherlands

J H HOEKSTRA, MD, physician

\title{
Comment
}

The diagnosis of rubella infection in case 1 seemed clear. From the anamnesis we concluded that the infection had occurred in early

\section{Lepromatous leprosy presenting with swelling of the legs}

In the various forms of leprosy, and including the adverse reactions associated with either cell-mediated or humoral (immune-complex) responses, oedema is well recognised, though its cause is not fully understood. We report a case in which seven years after arriving in Britain a Pakistani man was found to have lepromatous leprosy after presenting with swelling of the legs and superficial phlebitis.

\section{Case report}

A 50-year-old Pakistani man presented at a varicose vein clinic with swelling of the legs and giving a vague history of varicose eczema and recurrent phlebitis. Examination confirmed pitting oedema of the feet and ankles and tender areas of inflammation along the superficial veins. Although there was neither eczema nor varicose ulceration he was referred to a dermatological clinic by which time he was feverish, looked ill, and had soft-tissue swelling of the nose, cheeks, forehead, and ears. There were tender nodules, about $1 \mathrm{~cm}$ in diameter, over the thighs, lower legs, and extensor surface of the forearms, and larger, less well-defined lesions-raised, red, not tender on palpation - on the calves, knee regions, and thighs. Oedema of the legs was unusually firm and reached almost to the knees; the overlying skin had a shiny "mahogany woodgrain" pattern. Nothing abnormal was found on palpation of the peripheral nerves but cotton-wool testing showed anaesthesia of an incomplete "glove-and-stocking" type in the hands and feet. The testicles were atrophic and painless on pressure. Fresh blood was present in the right nasal vestibule.

From 1970 to 1975 he attended an ear, nose, and throat clinic on several occasions with deafness and ear inflammation, and in the year before diagnosis he developed nasal blockage and epistaxis, the latter needing cauterisation and packing on several occasions.

Zichl-Neelsen staining of slit-skin smears from ears, cheeks, and arm and leg lesions disclosed numerous Mycobacterium leprae. Nasal smears and noseblow material were strongly positive for acid-fast bacilli, and biopsy specimens from an arm nodule, left ear lobe, and left nostril showed typical lepromatous histopathology. Two of these biopsy specimens, however, also showed areas of vasculitis and infiltration by polymorphs. A lepromin test gave negative results at four weeks.

The type of leprosy was judged to be lepromatous with features of immune-complex reaction, as evidenced by erythema nodosum leprosum in the skin, increased erythrocyte sedimentation rate, fever, malaise, pain, and 